Research Paper

\title{
Multidisciplinary palliation for unresectable recurrent rectal cancer: hypoxic pelvic perfusion with mitomycin $C$ and oxaliplatin in patients progressing after systemic chemotherapy and radiotherapy, a retrospective cohort study
}

\author{
Stefano Guadagni ${ }^{1}$, Giammaria Fiorentini ${ }^{2}$, Andrea Mambrini ${ }^{3}$, Francesco Masedu ${ }^{1}$, \\ Marco Valenti', Andrew Reay Mackay', Donatella Sarti ${ }^{2}$, Enrico Ricevuto ${ }^{1,4}$, \\ Marco Clementi ${ }^{1}$, Marco Catarci ${ }^{5}$, Gianni Lazzarin' and Gemma Bruera ${ }^{1,4}$ \\ ${ }^{1}$ Department of Applied Clinical Sciences and Biotechnology, University of L'Aquila, L'Aquila, Italy \\ ${ }^{2}$ Department of Oncology and Hematology, Azienda Ospedaliera "Ospedali Riuniti Marche Nord", Pesaro, Italy \\ ${ }^{3}$ Oncology Unit, Azienda USL Toscana Nord Ovest, Massa Carrara, Italy \\ ${ }^{4}$ Oncology Territorial Care S. Salvatore Hospital, Oncology Network ASL1 Abruzzo, L'Aquila, Italy \\ ${ }^{5}$ General Surgery Unit, "C. e G. Mazzoni" Hospital, Ascoli Piceno, Italy \\ Correspondence to: Stefano Guadagni, email: stefano.guadagni@univaq.it \\ Keywords: hypoxic pelvic perfusion with mitomycin C and oxaliplatin; unresectable recurrent rectal cancer; retrospective cohort \\ study \\ Received: April 04, $2019 \quad$ Accepted: May 05, $2019 \quad$ Published: June 11, 2019 \\ Copyright: Guadagni et al. This is an open-access article distributed under the terms of the Creative Commons Attribution License \\ 3.0 (CC BY 3.0), which permits unrestricted use, distribution, and reproduction in any medium, provided the original author and \\ source are credited.
}

\section{ABSTRACT}

Background: Innovative systemic treatments and loco-regional chemotherapy by hypoxic pelvic perfusion (HPP) have been proposed for unresectable recurrent rectal cancer (URRC). Regorafenib and trifluridine-tipiracil reported significantly increased PFS 1.9-2.0 months, OS 6.4-7.1 months vs placebo, respectively. Present study evaluated safety and efficacy of mitomycin/oxaliplatin HPP associated to intravenous cetuximab, and of third line systemic therapy in clinical practice.

Methods: HPP consisted of: isolation, perfusion, chemofiltration. Patients received mitomycin $25 \mathrm{mg} / \mathrm{m}^{2}$ and oxaliplatin $80 \mathrm{mg} / \mathrm{m}^{2}$ during HPP; from days 21 to 28 , cetuximab $250 \mathrm{mg} / \mathrm{m}^{2} /$ week. In case of partial response or stable disease, HPPs were repeated every 8 weeks. In control group, systemic third and further lines of therapy were defined in clinical practice according to clinical (age, comorbidities, performance status), biological parameters (KRAS, NRAS, BRAF genotype).

Results: From 2005 to 2018, 49 URRC patients were enrolled; 33 in HPP/targettherapy, 16 in systemic therapy control group. No HPP related complications were reported. Most common adverse events were skin, bone marrow toxicities. In HPP/ target-therapy group, ORR and DCR were 36.4 and $100 \%$; in systemic therapy control group, 18.7 and $31.25 \%$, respectively. In HPP/target-therapy compared with systemic therapy group, respectively, DCR seemed significantly favourable $(P=0.001)$, as PFS 8 vs 4 months $(P=0.018)$, and OS 15 vs 8 months $(P=0.044)$.

Conclusions: Present data showed that integration of HPP/target-therapy may be effective in local control, and efficacy as third line treatment of URCC patients. This therapeutic strategy deserves further prospective randomized trials to be compared to conventional systemic treatments. 


\section{INTRODUCTION}

The incidence of local recurrence in rectal cancer has decreased to approximately $8 \%$ in the last years [1]. Unfortunately, $50 \%$ of recurrent cancers are evaluated as unresectable in high volume specialist centers [2]. For unresectable recurrent rectal cancer (URRC) patients in progression after systemic chemotherapy and radiation, several palliative therapies have been proposed [3-5]. In real life experience of metastatic colorectal cancer (mCRC) patients progressing after an intensive first line FIr-B/FOx [6-8], or FIr-C/FOx-C [9], treatment in fit patients, or conventional medical treatment regimens in unfit patients $[10,11]$, we reported a median progression-free survival (PFS) of 10 months and an overall survival (OS) of 14 months. Recently, third line treatments with the multitargeted tyrosine kinase inhibitor regorafenib $[12,13]$, and the cytotoxic drug trifluridine/tipiracil (TAS-102), consisting of the association between trifluorothymidine, and thymidinephosphorilase-tipiracil, that inhibits trifluorothymidine degradation [14], of mCRC patients showed increased efficacy compared with placebo controls in randomized studies. Regorafenib addition to best supportive care increased $\mathrm{OS}$ in $\mathrm{mCRC}$ patients who have received all approved standard therapies [12]: median PFS 1.9 vs 1.7 months, median OS 6.4 vs 5.0 months, in the regorafenib compared to placebo arm. In the Recourse trial [14], evaluating TAS-102, all the patients had received prior chemotherapy regimens containing fluoropyrimidine, oxaliplatin, and irinotecan, all but one patient had received bevacizumab, all but two patients with KRAS wild-type tumors had received cetuximab or panitumumab; median PFS was 2.0 vs 1.7 months, median OS was 7.1 vs 5.3 months, in the TAS-102 compared with placebo group, respectively.

Few specialists centers performed palliative locoregional chemotherapy by hypoxic pelvic perfusion (HPP) [15]. HPP is a reasonably complex procedure that integrates the multidisciplinary competence of surgeons, radiologists and perfusionists, and involves isolation of the pelvic circulation by blocking blood flow in the aorta and inferior vena cava with balloon catheters, and at thigh-level with pneumatic cuffs [15]. The rationale of this loco-regional chemotherapeutic approach is based upon the possibility to expose tumors to high drug concentrations within the perfused compartment, and the use of chemotherapeutic agents, such as mitomycin $\mathrm{C}$, that exhibit enhanced toxicity under conditions of hypoxia $[16,17]$. Pharmacokinetic studies demonstrated that HPP can be interchangeably performed by either surgical [18], or percutaneous approaches $[19,20]$. With respect to efficacy, median survival times from initial HPP range between 10 to 20 months in nonhomogeneous studies in pretreated patients with
HPP-procedures associated to mono- or combination chemotherapy [21], single or repetitive treatments and high (cisplatin $170 \mathrm{mg} / \mathrm{m}^{2}, 5$-fluorouracil $1000 \mathrm{mg} / \mathrm{m}^{2}$ ) [22] or low drug mitomycin $\mathrm{C}\left(25 \mathrm{mg} / \mathrm{m}^{2}\right)$ dosages [23]. We recently reported that HPP associated to mitomycin $\mathrm{C}\left(25 \mathrm{mg} / \mathrm{m}^{2}\right)$ in patients with URRC in progression after systemic chemotherapy and radiotherapy, provided tumor response rate $40 \%$, median PFS 6 months, and median OS 10 months [23].

The purpose of this retrospective cohort study of URRC patients in progression after two lines of systemic chemotherapy and radiotherapy was to evaluate safety and efficacy of a cohort of patients treated with mitomycin/ oxaliplatin HPP associated to intravenous cetuximab, and a control cohort of patients treated with third and further lines of systemic therapy. This control cohort was based on URRC patients progressing to second line chemotherapy included in our previously reported real life experience of mCRC patients [6-11].

\section{RESULTS}

\section{Patients characteristics}

Over the years from 2005 to 2018,49 patients with unresectable recurrent rectal cancer (URRC), progressing after two lines of systemic chemotherapy and radiotherapy were enrolled; 33 patients were treated in HPP/target-therapy cohort (mitomycin/oxaliplatin HPP associated to intravenous cetuximab) and 16 patients in the systemic therapy control group (all conventional systemic treatments according to patients fitness, age, performance status (PS), and comorbidity status). A cross-sectional study identified patient demographic and baseline data, displayed in Table 1. Recurrences were subdivided in three groups using a modified Yamada's classification [24]: localized (including cases with invasion of uterus, vagina, bladder, prostate, and seminal vesicles), sacral, and lateral. Based on Eastern Cooperative Oncology Group (ECOG) classification (approximately $80 \%$ ECOG 3 ) and symptoms as pain, tiredness, and lack of appetite, the clinical profile of severity burden was between moderate and severe for all 49 patients [25].

\section{Adverse events}

No technical, hemodynamic or vascular complications were detected during HPP procedures and vascular cannulation was possible in all cases. There were no treatment-related deaths. Procedure-related complications and toxicities are listed in Table 2. The most common treatment-related adverse reactions were skin toxicity and bone marrow hypocellularity. No grade 4 hematological toxicity was observed in either group and 
no serious myelosuppression occurred. No significant differences were detected between groups using notparametric tests.

\section{Tumor response}

Table 3 shows the results of tumor response evaluated according to RECIST 1.1, considering the two first treatments of the third line for both groups. Among the 33 patients in the HPP/target-therapy group, twelve $(36.4 \%)$ partial responses (PRs), and twentyone $(63.6 \%)$ stable diseases (SDs) were observed; the objective response rate (ORR) and disease control rate (DCR) were $36.4 \%$ and $100 \%$, respectively. Among the 16 patients in the systemic therapy control group, three (18.7\%) PRs, two (12.5\%) SDs, and eleven (68.7\%) progressive diseases (PDs) were observed; the ORR and DCR were 18.7 and $31.25 \%$, respectively. The HPP/ target-therapy group provided a significantly higher DCR in comparison to the systemic therapy control group $(\mathrm{P}=0.001)$.

Among 26 PS3 patients treated with HPP, an improvement to PS2 was reported in 6 patients after treatment $(23 \%)$.

\section{Survival}

The median follow-up time was 14 (iqr 9 - 27) months. At the end of the follow-up period, $1(3 \%)$ patient in the HPP/target therapy group and $1(6.0 \%)$ patients in the systemic therapy control group were still alive. A Kaplan-Meier survival analysis showed significant differences between the two groups in terms of PFS and OS. The median PFS (from first treatment of the third line) was 8 (iqr 7 -16) months in the HPP/target therapy group and 4 (iqr 3.5 - 7) months in the systemic therapy control group, respectively $(\mathrm{P}=0.018)$ (Figure $1 \mathrm{~A})$. The median OS (from first treatment of the third line) was 15 (iqr 11 - 28) months in the HPP/target therapy group and 8 (iqr 4 - 19.5) months in the systemic therapy control group (P $=0.044)$ (Figure 1B).

The Cox univariate and multivariate analysis identified several prognostic factors of PFS and OS (Table 4). The univariate analysis demonstrated that the third line treatment modality, modified Yamada's classification [24], and ECOG displayed a significant association with PFS (Table 4-Part A). Of these, the third line treatment modality $(\mathrm{HR}=2.306,95 \% \mathrm{CI}$ 1.187 - 4.479, $\mathrm{P}=0.014)$, and modified Yamada's classification [24] (HR $=6.158,95 \%$ CI $2.321-16.337$, $\mathrm{P}=0.001)$ were further confirmed by multivariate analysis to be independent predictive factors for PFS. The univariate analysis demonstrated that the third line treatment modality, gender, age, modified Yamada's classification [24], and ECOG displayed an association with OS $(\mathrm{P}<0.10)$. Of these, the modality of third line treatment $(\mathrm{HR}=6.175,95 \%$ CI $2.726-13.989, \mathrm{P}=$ $0.001)$, age $\leq 60$ years $(\mathrm{HR}=2.282,95 \%$ CI 1.089 - 4.779, $\mathrm{P}=0.029)$, type sacral versus localized of modified Yamada's classification $(\mathrm{HR}=2.749,95 \% \mathrm{CI}$ $1.214-6.225, \mathrm{P}=0.015$ ), type lateral versus localized of modified Yamada's classification $(\mathrm{HR}=15.809$, $95 \% \mathrm{CI} 4.813-51.928, \mathrm{P}=0.001)$, and ECOG $(\mathrm{HR}=$ $22.637,95 \%$ CI $5.844-87.681, \mathrm{P}=0.001$ ) were further confirmed by multivariate analysis to be independent predictive factors for OS.

Median overall survival from recurrent rectal cancer diagnosis to death or end of follow-up (RRC-OS) was 30 (iqr 21 - 42) months.

Among HPP procedure group, patients did not underwent subsequent lines of treatment. Among patients treated with systemic treatments, 5 underwent further lines $(30 \%)$.

\section{DISCUSSION}

The management of URRC requires a multidisciplinary approach and when standard treatments such as systemic chemotherapy and radiotherapy failed or are impracticable, the combination of a locoregional chemotherapy modality, as HPP, and systemic therapy may be an alternative option and it is under investigation [19]. This is the first paper evaluating combination of locoregional chemotherapy and systemic therapy versus a historical control of systemic therapy as third line for URRC, defined in clinical practice according to clinical (age, comorbidities, performance status), biological parameters (KRAS, NRAS, BRAF genotype).

The historical control of URRC patients, progressing after second line treatments and included in our previously reported real life experience of overall pre-treated mCRC patients, showed a median OS of 4 months, consisting with the median OS of approximately 5 months for the control arms in recently reported phase III trials indicating regorafenib or TAS-102 as innovative third line treatments $[13,14]$.

The present study showed that the DCR of the HPP/target-therapy group (mitomycin, oxaliplatin and cetuximab) seems non inferior but also potentially significantly higher $(\mathrm{P}=0.001)$ than the systemic therapy control group, suggesting that the locoregional and systemic combination regimen may be beneficial for the short-term control of URRC lesions. Patients treated with HPP approach were prevalently PS3, approximately $80 \%$, due to disease related symptoms burden, thus suggesting the potential benefits of this treatment also in terms of palliative care. The analysis of efficacy seems to show that median PFS (from the first third line treatment) of the HPP/target-therapy group and the systemic therapy control group were 8 months and 4 months, respectively, 
Table 1: Characteristics of the 49 URRC patients submitted to HPP/target-therapy or systemic therapy

\begin{tabular}{|c|c|c|c|c|c|}
\hline & $\begin{array}{l}\text { All patients } \\
\quad(n=49)\end{array}$ & $\begin{array}{l}\text { HPP/target- } \\
\text { therapy group } \\
(\mathbf{n}=33)\end{array}$ & $\begin{array}{c}\text { Systemic } \\
\text { therapy group } \\
(\mathrm{n}=16)\end{array}$ & $P$ value & Test \\
\hline Gender & & & & $0.437(\mathrm{~ns})$ & Student't \\
\hline - Male & 33 & 21 & 12 & & \\
\hline - Female & 16 & 12 & 4 & & \\
\hline $\begin{array}{l}\text { Age (years, median/iqr) at } \\
\text { the } 1^{\text {st }} \text { treatment of the } 3^{\text {rd }} \\
\text { line }\end{array}$ & $61 / 56-68$ & $60 / 56-65$ & $67.5 / 57-69$ & $0.108(\mathrm{~ns})$ & Mann-Whitney \\
\hline \multicolumn{6}{|l|}{$\begin{array}{l}\text { Previous treatments of } \\
\text { primary tumor }\end{array}$} \\
\hline - neo-adjuvant chemo/RT & 6 & 4 & 2 & $0.970(\mathrm{~ns})$ & Chi square \\
\hline - abdominoperineal resection & 28 & 19 & 9 & $0.930(\mathrm{~ns})$ & Chi square \\
\hline - low anterior resection & 21 & 14 & 7 & $0.930(\mathrm{~ns})$ & Chi square \\
\hline - adjuvant chemo/RT & 18 & 12 & 6 & $0.938(\mathrm{~ns})$ & Chi square \\
\hline \multicolumn{6}{|l|}{$\begin{array}{l}\text { Previous treatments of } \\
\text { recurrence }\end{array}$} \\
\hline - Systemic therapy & 49 & 33 & 16 & Not applicable & \\
\hline --chemotherapy & 49 & 33 & 16 & Not applicable & \\
\hline ---Fluorouracil & 48 & 33 & 15 & $0.327(\mathrm{~ns})$ & Fisher exact \\
\hline ---Oxaliplatin & 48 & 33 & 15 & $0.327(\mathrm{~ns})$ & Fisher exact \\
\hline ---Irinotecan & 49 & 33 & 16 & Not applicable & \\
\hline ---Capecitabine & 7 & 5 & 2 & $1.000(\mathrm{~ns})$ & Fisher exact \\
\hline --targeted-therapy & 45 & 30 & 15 & $1.000(\mathrm{~ns})$ & Fisher exact \\
\hline --cetuximab & 12 & 8 & 4 & $1.000(\mathrm{~ns})$ & Fisher exact \\
\hline --bevacizumab & 44 & 29 & 15 & $1.000(\mathrm{~ns})$ & Fisher exact \\
\hline - RT & 12 & 9 & 3 & $0.515(\mathrm{~ns})$ & Chi square \\
\hline - Surgery & 11 & 10 & 1 & 0.076 (ns) & Fisher exact \\
\hline \multicolumn{6}{|l|}{$\begin{array}{l}\text { Yamada's modified } \\
\text { classification }^{20}\end{array}$} \\
\hline - localized $(*)$ & 13 & 9 & 4 & $0.891(\mathrm{~ns})$ & Student't \\
\hline - sacral & 27 & 18 & 9 & & \\
\hline - lateral & 9 & 6 & 3 & & \\
\hline \multicolumn{6}{|l|}{ Other metastatic sites } \\
\hline- not & 22 & 16 & 6 & $0.479(\mathrm{~ns})$ & Student't \\
\hline - yes & 27 & 17 & 10 & & \\
\hline
\end{tabular}

(Continued) 


\begin{tabular}{|c|c|c|c|c|c|}
\hline & $\begin{array}{l}\text { All patients } \\
\quad(n=49)\end{array}$ & $\begin{array}{l}\text { HPP/target- } \\
\text { therapy group } \\
\quad(n=33)\end{array}$ & $\begin{array}{c}\text { Systemic } \\
\text { therapy group } \\
(n=16)\end{array}$ & $P$ value & Test \\
\hline \multicolumn{6}{|l|}{$\begin{array}{l}\text { Eastern Cooperative } \\
\text { Oncology Group (ECOG) }\end{array}$} \\
\hline-3 & 39 & 26 & 13 & 0.845 (ns) & Student't \\
\hline-2 & 10 & 7 & 3 & & \\
\hline $\begin{array}{l}\text { Interval time from URRC } \\
\text { diagnosis and the } 1^{\text {st }} \\
\text { treatment of the } 3^{\text {rd }} \text { line } \\
\text { (months, median/iqr) }\end{array}$ & $13 / 10-16$ & $13 / 10-16$ & $14 / 10.5-30$ & $0.211(\mathrm{~ns})$ & Mann-Whitney \\
\hline $\begin{array}{l}\text { Number of cycles of the } 3^{\text {rd }} \\
\text { line (mean/SD) }\end{array}$ & $2.61 / 1.40$ & $2.36 / 1.50$ & $3.12 / 1.02$ & 0.07 (ns) & Student't \\
\hline Samples evaluated for ${ }^{\#}$ & & & & Not applicable & \\
\hline KRAS genotype & 19 & 3 & 16 & & \\
\hline wild-type & 12 & 3 & 9 & & \\
\hline mutant & 8 & - & 7 & & \\
\hline NRAS genotype & 3 & 3 & - & & \\
\hline BRAF genotype & 6 & - & 6 & & \\
\hline wild-type & 6 & - & 6 & & \\
\hline mutant & - & - & - & & \\
\hline
\end{tabular}

$\mathrm{Chemo} / \mathrm{RT}=$ systemic chemotherapy/radiotherapy; iqr = interquartile range; $\mathrm{SD}=$ standard deviation; $\left({ }^{*}\right)$ this group included cases with invasion of uterus, vagina, bladder, prostate, seminal vesicles; URRC $=$ unresectable recurrent rectal cancer; "anti-EGFR drugs administered according to racommendations alongtime (evaluation of EGFR overexpression, KRAS exon 2 wild-type, KRAS/NRAS exon 2-4 wild-type).

Table 2: Procedure-related complications and toxicities in 49 URRC patients submitted to HPP/target-therapy or systemic therapy

\begin{tabular}{|c|c|c|c|c|}
\hline Part A: Procedure-related complications & Grade & $\begin{array}{l}\text { All patients } \\
\quad(n=49)\end{array}$ & $\begin{array}{l}\text { HPP/target- } \\
\text { therapy group } \\
\quad(n=33)\end{array}$ & $\begin{array}{c}\text { Systemic } \\
\text { therapy group } \\
(\mathrm{n}=16)\end{array}$ \\
\hline Persistent leakage of fluid from the incision & 2 & 1 & 1 & 0 \\
\hline Seroma & 1 & 1 & 1 & 0 \\
\hline Wound infection & 1 & 1 & 1 & 0 \\
\hline Scrotum edema & 1 & 1 & 1 & 0 \\
\hline Pelvic pain & 1 & 2 & 1 & 1 \\
\hline Inguinal hematoma & 1 & 1 & 1 & 0 \\
\hline Port-a-cath infection & 2 & 1 & 0 & 1 \\
\hline Part B: Procedure-related toxicities & Grade & $\begin{array}{l}\text { All patients } \\
(n=49)\end{array}$ & $\begin{array}{l}\text { HPP/target- } \\
\text { therapy group } \\
(n=33)\end{array}$ & $\begin{array}{c}\text { Systemic } \\
\text { therapy group } \\
(n=16)\end{array}$ \\
\hline \multirow[t]{2}{*}{ Bone marrow hypocellularity } & 1 & 8 & 4 & 4 \\
\hline & 2 & 0 & 0 & $\begin{array}{c}0 \\
\text { (Continued) }\end{array}$ \\
\hline
\end{tabular}




\begin{tabular}{lcccc}
\hline Part B: Procedure-related complications & Grade & $\begin{array}{c}\text { All patients } \\
(\mathbf{n}=\mathbf{4 9 )}\end{array}$ & $\begin{array}{c}\text { HPP/target- } \\
\text { therapy group } \\
(\mathbf{n}=\mathbf{3 3})\end{array}$ & $\begin{array}{c}\text { Systemic } \\
\text { therapy group } \\
(\mathbf{n}=\mathbf{1 6})\end{array}$ \\
\hline & 3 & 4 & 2 & 2 \\
Platinum-induced neurotoxicity & 2 & 4 & 2 & 2 \\
Alopecia & 2 & 2 & 2 & 0 \\
Nausea and vomiting & 1 & 4 & 3 & 1 \\
Diarrhea & 1 & 2 & 0 & 2 \\
& 2 & 4 & 0 & 4 \\
Mucositis & 3 & 1 & 0 & 1 \\
Fatigue & 1 & 5 & 2 & 0 \\
Skin toxicity & 2 & 2 & 4 & 2 \\
& 1 & 6 & 12 & 6 \\
\hline
\end{tabular}

Table 3: Comparison of response between the HPP/target-therapy group and Systemic therapy control group in 49 URRC patients

\begin{tabular}{lcccc}
\hline Outcome & $\begin{array}{c}\text { HPP/target-therapy } \\
\text { group }(\mathbf{n}=\mathbf{3 3})\end{array}$ & $\begin{array}{c}\text { Systemic therapy } \\
\text { group }(\mathbf{n}=\mathbf{1 6})\end{array}$ & $\chi^{2}$ & $\boldsymbol{P}$ value \\
\hline $\begin{array}{l}\text { Partial response (PR) } \\
\text { Stable disease (SD) }\end{array}$ & $12(36.36 \%)$ & $3(18.75 \%)$ & 29.782 & 0.001 \\
$\begin{array}{l}\text { Progressive disease } \\
\text { (PD) }\end{array}$ & $21(63.64 \%)$ & $2(12.50 \%)$ & & \\
$\begin{array}{l}\text { Objective response } \\
\text { rate (ORR) }\end{array}$ & $12(0.00 \%)$ & $11(68.75 \%)$ & 1.573 & $0.210(\mathrm{~ns})$ \\
$\begin{array}{l}\text { Disease control rate } \\
(\mathrm{DCR})\end{array}$ & $33(100 \%)$ & $3(18.7 \%)$ & 29.255 & 0.001 \\
\hline
\end{tabular}
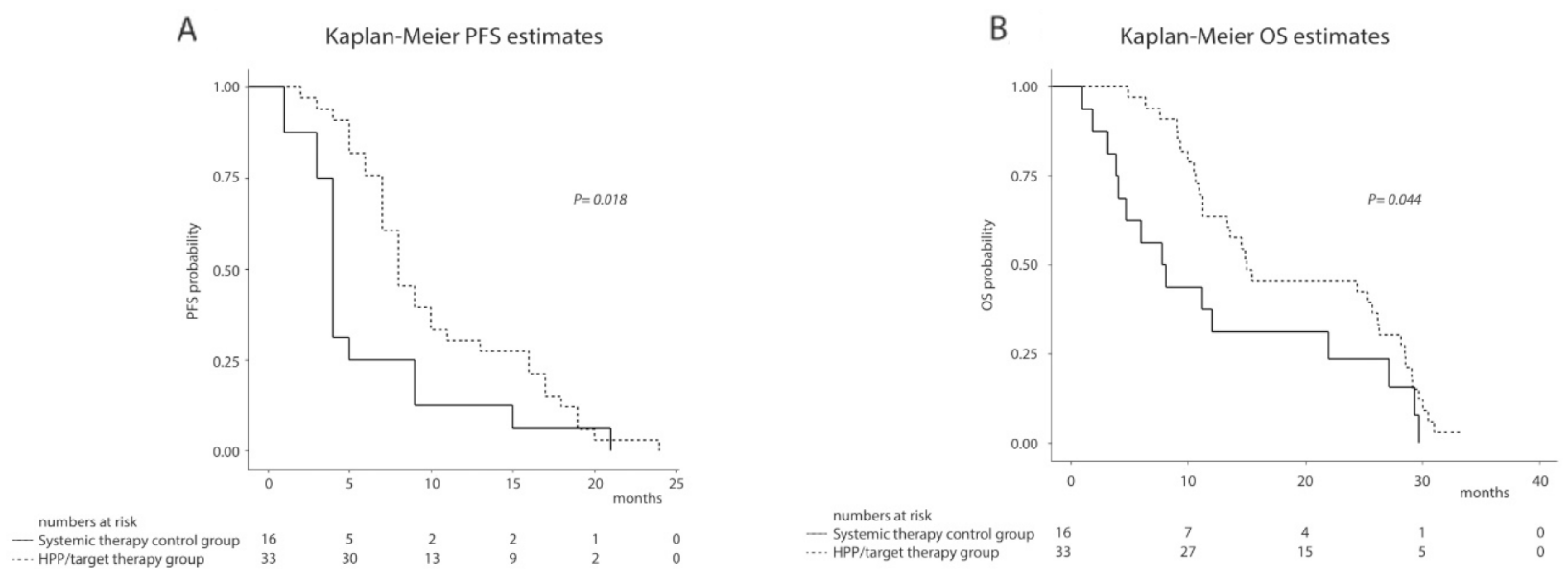

Figure 1: Kaplan-Meier survival estimates in 49 URRC patients from first treatment of the third line to end of follow-up: (A) Progression free survival; (B) Overall survival. 
Table 4: Part A: Progression free survival (PFS) times from first treatment of the third line to death or last contact in 49 URRC patients in progression after two lines systemic chemotherapy and radiotherapy. Patients were stratified according to third line treatment modality, gender, age, Yamada's modified classification, other sites of metastases, and ECOG. Part B: Survival times

\begin{tabular}{|c|c|c|c|c|c|}
\hline \multicolumn{6}{|l|}{$\begin{array}{l}\text { Part A-Progression free } \\
\text { survival }\end{array}$} \\
\hline $\begin{array}{l}\text { Variables (number of } \\
\text { patients) }\end{array}$ & $\begin{array}{c}\text { Median } \\
\text { (months)/iqr }\end{array}$ & $\begin{array}{c}\text { Log-Rank } \\
\chi^{2}\end{array}$ & $P$ value & HR (95\% CI) & $P$ value \\
\hline \multicolumn{6}{|l|}{ Third line treatment } \\
\hline $\begin{array}{l}\text { - Systemic therapy control } \\
\text { group }(\mathrm{n}=16)\end{array}$ & $4 / 3.5-7$ & & & $1.984(1.071-3.673)$ & 0.029 \\
\hline $\begin{array}{l}\text { - HPP/target therapy group } \\
(\mathrm{n}=33)\end{array}$ & $8 / 7-16$ & 5.52 & 0.019 & & \\
\hline \multicolumn{6}{|l|}{ Gender } \\
\hline - Male $(n=33)$ & $6 / 4-10$ & & & $1.156(0.625-2.137)$ & $0.644(\mathrm{~ns})$ \\
\hline - Female $(\mathrm{n}=16)$ & $9 / 7-14$ & 0.24 & $0.622(\mathrm{~ns})$ & & \\
\hline \multicolumn{6}{|l|}{ Age } \\
\hline$-\leq 60(n=24)$ & $7 / 5-10.5$ & & & $0.918(0.519-1.623)$ & $0.769(\mathrm{~ns})$ \\
\hline$->60(n=25)$ & $8 / 4-13$ & 0.10 & $0.755(\mathrm{~ns})$ & & \\
\hline \multicolumn{6}{|l|}{$\begin{array}{l}\text { Yamada's modified } \\
\text { classification }{ }^{20}\end{array}$} \\
\hline - localized* $(n=13)$ & $9 / 7-17$ & & & & \\
\hline - sacral $(n=27)$ & $7 / 4-15$ & & & $1.277(0.654-2.494)$ & 0.473 (ns) \\
\hline - lateral $(n=9)$ & $3 / 2-5$ & 13.41 & 0.001 & $4.069(1.669-9.917)$ & 0.002 \\
\hline \multicolumn{6}{|l|}{ Other sites of metastases } \\
\hline - Yes $(n=27)$ & $7 / 4-10$ & & & $1.197(0.676-2.116)$ & $0.537(\mathrm{~ns})$ \\
\hline$-\operatorname{Not}(n=22)$ & $8 / 5-16$ & 0.43 & 0.512 & & \\
\hline \multicolumn{6}{|l|}{ ECOG } \\
\hline$-3(n=39)$ & $7 / 4-10$ & & & $2.073(0.987-4.352)$ & 0.054 \\
\hline$-2(n=10)$ & $9 / 8-19$ & 4.34 & 0.037 & & \\
\hline \multicolumn{6}{|l|}{ Part B - Survival } \\
\hline $\begin{array}{l}\text { Variables (number of } \\
\text { patients) }\end{array}$ & $\begin{array}{c}\text { Median } \\
\text { (months)/iqr }\end{array}$ & $\begin{array}{c}\text { Log-Rank } \\
\chi^{2} \\
\end{array}$ & P value & HR (95\% CI) & $P$ value \\
\hline \multicolumn{6}{|l|}{ Third line treatment } \\
\hline $\begin{array}{l}\text { - Systemic therapy control } \\
\text { group }(n=16)\end{array}$ & $8 / 4-19.5$ & & & $1.799(0.969-3.343)$ & 0.063 \\
\hline $\begin{array}{l}\text { - HPP/target therapy group } \\
(\mathrm{n}=33)\end{array}$ & $15 / 11-28$ & 4.05 & 0.044 & & \\
\hline \multicolumn{6}{|l|}{ Gender } \\
\hline - Male $(\mathrm{n}=33)$ & $11 / 8-26$ & & & $1.678(0.905-3.112)$ & $0.100(\mathrm{~ns})$ \\
\hline - Female $(\mathrm{n}=16)$ & $24.5 / 14-29$ & 3.19 & 0.074 & & \\
\hline
\end{tabular}

(Continued) 


\begin{tabular}{|c|c|c|c|c|c|}
\hline \multicolumn{6}{|l|}{ Part B - Survival } \\
\hline $\begin{array}{l}\text { Variables (number of } \\
\text { patients) }\end{array}$ & $\begin{array}{c}\text { Median } \\
\text { (months)/iqr }\end{array}$ & $\begin{array}{c}\text { Log-Rank } \\
\chi^{2} \\
\end{array}$ & P value & HR $(95 \%$ CI $)$ & P value \\
\hline \multicolumn{6}{|l|}{ Age } \\
\hline$-\leq 60(n=24)$ & $13.5 / 9-24.5$ & & & $0.616(0.339-1.118)$ & $0.111(\mathrm{~ns})$ \\
\hline$->60(n=25)$ & $15 / 8-29$ & 2.92 & 0.088 & & \\
\hline \multicolumn{6}{|l|}{$\begin{array}{l}\text { Yamada's modified } \\
\text { classification }{ }^{20}\end{array}$} \\
\hline - localized* $(n=13)$ & $27 / 22-29$ & & & & 0.003 \\
\hline - sacral $(\mathrm{n}=27)$ & $12 / 8-26$ & & & $1.605(0.816-3.157)$ & \\
\hline - lateral $(\mathrm{n}=9)$ & $6 / 3-11$ & 10.68 & 0.005 & $3.765(1.566-9.049)$ & \\
\hline \multicolumn{6}{|l|}{ Other sites of metastases } \\
\hline - Yes $(n=27)$ & $11 / 6-15$ & & & $1.532(0.855-2.743)$ & 0.151 \\
\hline$-\operatorname{Not}(\mathrm{n}=22)$ & $25.5 / 15-29$ & 2.41 & 0.120 & & \\
\hline \multicolumn{6}{|l|}{ ECOG } \\
\hline$-3(n=39)$ & $11 / 8-17$ & & & $\begin{array}{c}11.917(3.857- \\
36.817)\end{array}$ & 0.001 \\
\hline$-2(n=10)$ & $30 / 29-30$ & 25.57 & 0.001 & & \\
\hline
\end{tabular}

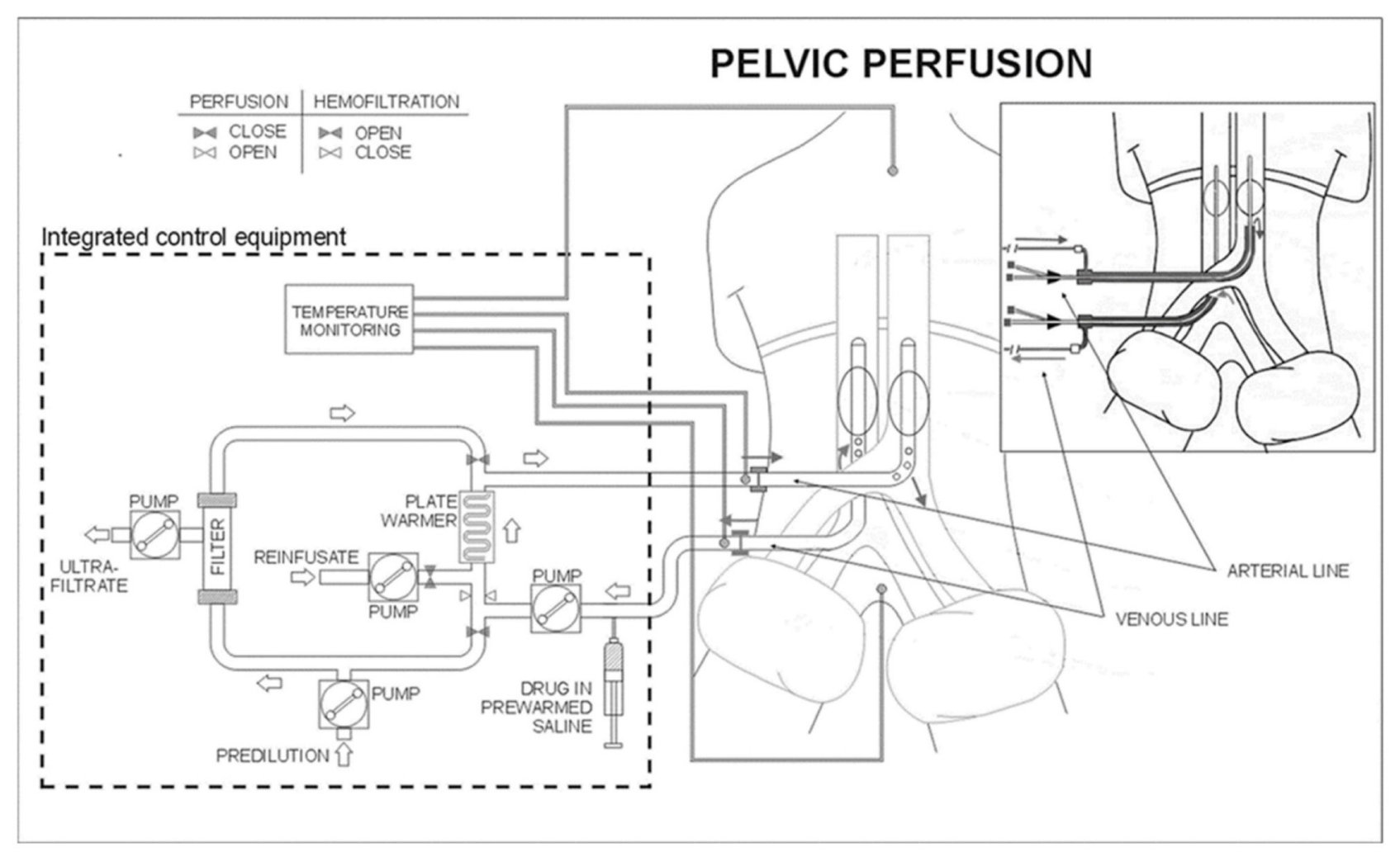

Figure 2: Schematic representation of the surgical and percutaneous hypoxic pelvic perfusion (HPP) procedures, with chemofiltration. 
with statistically significant difference between them (P $=0.018$ ); median OS (from the first third line treatment) of the HPP/target-therapy group and the systemic therapy control group were 15 and 8 months, respectively, with statistically significant difference between them $(\mathrm{P}=$ $0.044)$; the above results shows that URRC patients may benefit from combination of locoregional chemotherapy and systemic therapy. The multivariate analysis upon the 49 URRC patients evaluated in this study showed that the locoregional and systemic combination of treatment, age $>60$ years, localized type of recurrence, and ECOG 2 class may be independent predictors of prolonged OS. The pharmacokinetic and microenvironmental advantages of HPP associated to target-therapy, in terms of tumor drug exposure and enhanced activity under hypoxic condition for specific chemotherapeutic agents, provide a better control of localized rectal cancer recurrence in comparison to systemic therapy alone [26]. The present study demonstrated that the combination of locoregional and systemic therapy, as in other cancers [27], may provide benefit also in URRC patients with other metastatic sites.

Common adverse events were manifested as skin toxicity and bone marrow hypocellularity and there was no statistically significant difference between the two groups, indicating that URRC patients are tolerant of the two regimens and that HPP is, in general, safe and reliable, even with more limitations regarding different administered chemotherapy regimens. With respect to the tolerability of locoregional chemotherapy in association with chemofiltration, we confirm similar reports $[22,28]$, with absence of nephrotoxicity, severe neuropathy, and G4 hematological toxicity.

There were several limitations in the study: i) this study was conducted in a single center for homogeneity of HPP technique; ii) the study is retrospective and not prospective; iii) the number of cases is relatively low insufficient, and the results may be biased.

With limitations concerning retrospective evaluation and statistical relevance of OS results, present data show that in principle integration of HPP/target-therapy may be effective at symptomatic level in the local control, and in terms of long-term efficacy of URCC patients. In conclusion, HPP with mitomycin and oxaliplatin associated to cetuximab target-therapy is an efficient and safe alternative choice for third line treatment of URCC patients which deserves further prospective randomized trials.

\section{MATERIALS AND METHODS}

\section{Patient population}

This retrospective cohort study of patients with recurrent rectal cancer was enrolled at the University of L'Aquila, L'Aquila, Italy, after approval by the investigational review board [Ethics committee of "ASL n.1, Abruzzo, Italy; Chairperson: G. Piccioli; protocol number 10/CE/2018; date of approval: 19 July, 2018 (n.1419)], providing that all patients had unresectable disease. All patients received complete information about their disease and the implications of the proposed palliative treatment, in accordance with both Declaration of Helsinki and ethical standards of the committee on human experimentation at our institution, and written consent was obtained.

Patient eligibility criteria were: (i) histological diagnosis of adenocarcinoma of the rectum; (ii) diagnosis of unresectable recurrent rectal cancer, defined by pelvic side-wall involvement, and/or growth into the sciatic notch, and/or involvement of the first and/or second sacral vertebra, and/or encasement of the bladder or iliac vessels; (iii) an increase in recurrent tumor size for at least three months following systemic chemotherapy or radiation; (iv) a performance status of 0-3 based upon the Eastern Cooperative Oncology Group (ECOG) scale; (v) a leukocyte count $>2500$ cells $/ \mathrm{mm}^{3}$ and platelet count $>$ 50000 cells $/ \mathrm{mm}^{3}$; (vi) a serum Creatinine concentration of $\leq 1.2 \mathrm{mg} / \mathrm{dL}$; (vii) absence of liver failure, deep venous thrombosis, severe atherosclerosis, or coagulopathy; (viii) URRC patients in progression after two lines of systemic chemotherapy.

According to recommendations for administration of anti-epidermal growth factor receptor (anti-EGFR) drugs, tumoral samples of primary tumors or metastatic site were evaluated for EGFR expression, and mutations in KRAS (Kirsten rat sarcoma virus), NRAS (neuroblastoma RAS viral oncogene homolog) exon 2 codons 12 and 13, exon 3 codons 59 and 61 and, exon 4 codons 117 and 146, and BRAF genes.

\section{HPP techniques}

Prior to perfusion, patients were subjected to aortoiliac tree and inferior vena cava angiography or angio-computerized tomography (CT). Surgical or percutaneous perfusions were performed under general anesthesia. In patients exhibiting femoral vessel fibrosis, requiring 2 or 3 repeat perfusions, the surgical approach was achieved by exposing the iliac vessels. Percutaneous perfusion was not performed if the common femoral artery diameter was $\leq 7 \mathrm{~mm}$, making vessel dissection risky. The surgical approach was preferred for all patients and the percutaneous approach was reserved for patients submitted to more than 3 perfusions. HPP (Figure 2) comprised three phases: isolation, perfusion and chemofiltration, as previously described [19].

\section{Drugs regimens}

HPP/target therapy group schedule: at HPP, patients received mitomycin (Mitomycin C, Kyowa Kirin, Milan, Italy), at the dose of $25 \mathrm{mg} / \mathrm{m}^{2}$ based on our previous 
studies [18, 19], and oxaliplatin (Eloxatin; Sanofi-Aventis, Milan, Italy), at the dose of $80 \mathrm{mg} / \mathrm{m}^{2}$ according to literature reports on locoregional chemotherapy palliation of metastatic colorectal cancer patients [29]. Starting from days 21 to 28 after HPP, if the local cutaneous toxicity was $\leq$ grade 1, patients received cetuximab (Erbitux; Merck, Darmstadt, Germany), at the dose of $250 \mathrm{mg}$ / $\mathrm{m}^{2}$, intravenous infusion in $\mathrm{NaCl} 0.9 \% 600 \mathrm{ml}$ over 120 minutes, days $1,8,15,22$. In patients exhibiting a partial response or stable disease, HPPs were repeated at intervals of approximately 8 weeks based upon a pilot study [18], in which progression was always observed in presence of residual tumor. Treatment was not repeated in patients exhibiting a complete response; if local recurrence or distant relapse had progressed $>20 \%$ in dimension; if simultaneous distant relapses occurred; if the general condition of the patient worsened or if the patient did not consent.

Systemic therapy control group schedules, defined according to clinical (age, comorbidities, performance status), and biological parameters (KRAS, NRAS, BRAF genotype): oxaliplatin (Eloxatin; Sanofi-Aventis, Milan, Italy) as 2-hours intravenous infusion in dextrose $5 \% 250 \mathrm{ml}, 70-80 \mathrm{mg} / \mathrm{m}^{2}$, days 1,15 [30], or irinotecan (Campto; Pfizer, Latina, Italy) $120-160 \mathrm{mg} / \mathrm{m}^{2}$, as 90 minutes intravenous infusion in $\mathrm{NaCl} 0.9 \% 250 \mathrm{ml}$, days 1, 15, added to cetuximab (Erbitux; Merck, Darmstadt, Germany), loading dose $400 \mathrm{mg} / \mathrm{m}^{2}$, followed by 250 $\mathrm{mg} / \mathrm{m}^{2}$, intravenous infusion in $\mathrm{NaCl} 0.9 \% 600 \mathrm{ml}$ over 120 minutes at first time, then in $300 \mathrm{ml}$ over 60 minutes, days $1,8,15,22$, every 28 days; panitimumab (Vectibix; Amgen, Breda, Netherlands) $6 \mathrm{mg} / \mathrm{kg}$, as 90 minutes intravenous infusion at first administration, 60 minutes at subsequent ones, in $\mathrm{NaCl} 0.9 \% 100 \mathrm{ml}$, days 1,15 , every 28 days; panitumumab added to irinotecan according to the previously reported administration modality; oxaliplatin added to timed-flat infusion 5-fluorouracil (Fluorouracil Teva; Teva Italia, Milan, Italy) 750-900 $\mathrm{mg} / \mathrm{m}^{2} /$ day, over 12-hour (from 10:00 p.m to 10:00 a.m.), days 1-2, 8-9, 15-16, 22-23; 5-fluorouracil added to bevacizumab (Avastin ${ }^{\circledR}$, Roche), $5 \mathrm{mg} / \mathrm{kg}$, administered over 90 minutes at the first, 60 minutes at the second and 30 minutes from the third time, intravenous infusion in $100 \mathrm{ml}$ of $\mathrm{NaCl} 0.9 \%$, days 1 and 15, every 28 days; raltitrexed (Tomudex, Hospira, Naples, Italy) $3 \mathrm{mg} /$ $\mathrm{m}^{2}$, as 15 minutes intravenous infusion in $\mathrm{NaCl} 0.9 \%$ $250 \mathrm{ml}$, days 1, every 21 days; capecitabine (Xeloda, Roche, Grenzach-Wyhlen, Germay) $825 \mathrm{mg} / \mathrm{m}^{2} /$ twice a day orally administered, days 1-14, every 21 days; regorafenib (Stivarga, Bayer, Leverkusen, Germany) 80$160 \mathrm{mg} /$ day, days 1-21, every 28 days. Treatment was discontinued in case of progressive disease, worsening of general conditions, severe adverse events, or patient withdrawal. In both groups, cetuximab and panitumumab were administered according to the following conditions: EGFR overexpression; absence of mutations in KRAS and NRAS exon 2 codons 12 and 13, exon 3 codons 59 and 61 and, and exon 4 codons 117 and 146, in recurrent cancer cells or primary tissues [31].

\section{Criteria for responses and adverse events}

Tumor responses were assessed in accordance with Response Evaluation Criteria in Solid Tumors (RECIST version 1.1), at 30-45 days following each treatment [32]. The responses of patients treated prior to 2009, were reclassified retrospectively. Responses were evaluated by CT, Magnetic Resonance Imaging (MRI), and Positionemission Tomography (PET). Adverse events were evaluated in accordance with the Common Terminology Criteria for Adverse Events of the National Cancer Institute (CTCAE v4.03).

\section{Statistical analysis}

Statistical analyses were performed using STATA software, version 14 (StataCorp, College Station, Texas). Statistics were calculated with $95 \%$ confidence limits. Statistical analyses were performed using t tests or MannWhitney tests for measurement data, and Chi-square tests or Fisher's exact tests for count data. Survival-rates were estimated using the Kaplan-Meier product limit estimator and no patients were lost during follow-up. Survival times were stratified according to clinical variables that may affect survival and log-rank tests were used to assess significant differences between groups. Hazard ratios were estimated using a proportional hazard Cox regression model. For both groups, progression-free survival-time (PFS) and overall survival (OS) were calculated from the first treatment of the third line to death or end of followup. RRC overall survival (RRC-OS) was calculated from diagnosis of RRC to death or end of follow-up.

\section{Author contributions}

SG contributed to the conception and design of the study, in the provision of study materials of patients, in the surgical management of patients, in the data analysis and interpretation, in the manuscript writing. GF, AM contributed in medical oncology patients' management. FM, MV contributed in data analysis and interpretation, and in the statistical design. ARM contributed in biological evaluations. DS contributed in data analysis and interpretation. ER contributed to the conception and design of the study, in clinical management of patients, in the data analysis and interpretation, in the manuscript writing. $\mathrm{MaCl}, \mathrm{MaCa}$, GL contributed in surgical management of patients. GB contributed to the conception and design of the study, in the provision of study materials of patients, in the clinical management of patients, in the data analysis and interpretation, in the manuscript writing. All authors participated in the 
collection and/or assembly of data. All authors read, revised and approved the final manuscript.

\section{ACKNOWLEDGMENTS}

We would like to thank Karl Reinard Aigner for his surgical teaching.

\section{CONFLICTS OF INTEREST}

The Authors declare that there is no conflicts of interest.

\section{FUNDING}

This research received no specific grants from any funding agency in the public, commercial, or not-for-profit sectors.

\section{REFERENCES}

1. Sammour T, Skibber JM. Evaluation of Treatment of Locally Recurrent Rectal Cancer. In: Chang G. (eds) Rectal Cancer. Springer, Cham. 2018. Pages 231-45. ISBN: 978-3-31916384-0. https://doi.org/10.1007/978-3-319-16384-0_14.

2. Lee D, Sagar P, Sadadcharam G, Tan KY. Advances in surgical management for locally recurrent rectal cancer: How far have we come? World J Gastroenterol. 2017; 23:4170-4180. https://doi.org/10.3748/wjg.v23.i23.4170. [PubMed]

3. Guadagni S, Aigner KR, Fiorentini G, Cantore M, Clementi M, Chiominto A, Zavattieri G, et al. Pelvic perfusion for rectal cancer. In: Aigner K., Stephens F. (eds) Induction Chemotherapy. Springer, Cham. 2016. Pages 293-307. ISBN: 978-3-319-28773-7. https://doi.org/10.1007/978-3-319-28773-7 20.

4. Lingareddy V, Ahmad NR, Mohiuddin M. Palliative reirradiation for recurrent rectal cancer. Int J Radiat Oncol Biol Phys. 1997; 38:785-790. https://doi.org/10.1016/S0360-3016(97)00058-8. [PubMed]

5. Susko M, Lee J, Salama J, Thomas S, Uronis H, Hsu D, Migaly J, Willett C, Czito B, Palta M. The use of re-irradiation in locally recurrent non-metastatic rectal cancer. Ann Surg Oncol. 2016; 23:3609-3615. https://doi.org/10.1245/s10434-016-5250-z. [PubMed]

6. Bruera G, Santomaggio A, Cannita K, Lanfiuti Baldi P, Tudini M, De Galitiis F, Mancini M, Marchetti P, Antonucci A, Ficorella C, Ricevuto E. "Poker" association of weekly alternating 5-fluorouracil, irinotecan, bevacizumab and oxaliplatin (FIr-B/FOx) in first line treatment of metastatic colorectal cancer: a phase II study. BMC Cancer. 2010; 10:567. https://doi.org/10.1186/1471-2407-10-567. [PubMed]

7. Bruera G, Cannita K, Giordano AV, Vicentini R, Ficorella C, Ricevuto E. Effectiveness and safety of intensive triplet chemotherapy plus bevacizumab, FIr-B/
FOx, in young-elderly Metastatic Colorectal Cancer (MCRC) patients. Biomed Res Int. 2013; 2013:143273. https://doi.org/10.1155/2013/143273. [PubMed]

8. Bruera G, Cannita K, Giordano AV, Vicentini R, Ficorella C, Ricevuto E. Differential prognosis of metastatic colorectal cancer patients post-progression to first line triplet chemotherapy plus bevacizumab, FIr-B/FOx, according to second line treatment and KRAS genotype. Int J Oncol. 2014; 44:17-26. https://doi.org/10.3892/ijo.2013.2179. [PubMed]

9. Bruera G, Massacese S, Pepe F, Malapelle U, Dal Mas A, Ciacco E, Calvisi G, Troncone G, Simmaco M, Ricevuto E. Intensive first-line FIr-C/FOx-C triplet chemotherapy plus cetuximab in RAS wild-type metastatic colorectal cancer patients: preliminary phase II data and prediction of individual limiting toxicity syndromes by pharmacogenomic biomarkers. Annals of Oncology. 2019; 29:5. https://doi.org/10.1093/annonc/mdy151.205.

10. Bruera G, Cannita K, Giordano AV, Vicentini R, Ficorella C, Ricevuto E. Prognostic relevance of KRAS genotype in metastatic colorectal cancer patients unfit for FIr-B/ FOx intensive regimen. Int J Oncol. 2014; 44:1820-1830. https://doi.org/10.3892/ijo.2014.2369. [PubMed]

11. Bruera G, Russo A, Galvano A, Rizzo S, Ricevuto E. Clinical parameters to guide decision-making in elderly metastatic colorectal CANCER patients treated with intensive cytotoxic and anti-angiogenic therapy. Oncotarget. 2017; 8:3787537883. https://doi.org/10.18632/oncotarget.14333. [PubMed]

12. Grothey A, Van Cutsem E, Sobrero A, Siena S, Falcone A, Ychou M, Humblet Y, Bouché O, Mineur L, Barone C, Adenis A, Tabernero J, Yoshino T, et al. Regorafenib monotherapy for previously treated metastatic colorectal cancer (CORRECT): an international, multicentre, randomised, placebo-controlled, phase 3 trial. Lancet. 2013; 381:303-312. https://doi.org/10.1016/S0140-6736(12)61900-X. [PubMed]

13. Li J, Qin S, Xu R, Yau TC, Ma B, Pan H, Xu J, Bai Y, Chi Y, Wang L, Yeh KH, Bi F, Cheng Y, et al. Regorafenib plus best supportive care versus placebo plus best supportive care in Asian patients with previously treated metastatic colorectal cancer (CONCUR): a randomised, double-blind, placebocontrolled, phase 3 trial. Lancet Oncol. 2015; 16:619629. https://doi.org/10.1016/S1470-2045(15)70156-7. [PubMed]

14. Mayer RJ, Van Cutsem E, Falcone A, Yoshino T, GarciaCarbonero R, Mizunuma N, Yamazaki K, Shimada Y, Tabernero J, Komatsu Y, Sobrero A, Boucher E, Peeters M, et al. Randomized Trial of TAS-102 for refractory Metastatic Colorectal Cancer. N Engl J Med. 2015; 372:1909-1919. https://doi.org/10.1056/NEJMoa1414325. [PubMed]

15. Guadagni S, Kanavos E, Schietroma M, Fiorentini G, Amicucci G. Selected hypoxic stop-flow perfusions: Indication and limits. Tumori. 2006; 92:402-406. https://doi.org/10.1177/030089160609200506. [PubMed]

16. Guadagni S, Clementi M, Valenti M, Fiorentini G, Cantore M, Kanavos E, Caterino GP, Di Giuro G, Amicucci G. Hypoxic abdominal stop-flow perfusion 
in the treatment of advanced pancreatic cancer: a phase II evaluation/trial. Eur J Surg Oncol. 2007; 33:72-78. https://doi.org/10.1016/j.ejso.2006.10.042. [PubMed]

17. Guadagni S, Aigner RK, Palumbo G, Cantore M, Fiorentini G, Pozone T, Deraco M, Clerico M, Chaudhuri PK. Pharmacokinetics of Mitomycin $\mathrm{C}$ in pelvic stopflow infusion and hypoxic pelvic perfusion with and without hemofiltration: a pilot study of patients with recurrent unresectable rectal cancer. J Clin Pharmacol. 1998; 38:936-944. https://doi.org/10.1002/j.1552-4604.1998.tb04390.x. [PubMed]

18. Guadagni S, Fiorentini G, Palumbo G, Valenti $M$, Russo F, Cantore M, Deraco M, Vaglini M, Amicucci G. Hypoxic pelvic perfusion with mitomycin $\mathrm{C}$ using a simplified balloon-occlusion technique in the treatment of patients with unresectable locally recurrent rectal cancer. Arch Surg. 2001; 136:105-112. https://doi.org/10.1001/archsurg.136.1.105. [PubMed]

19. Guadagni S, Fiorentini G, Clementi M, Palumbo P, Mambrini A, Masedu F. Mitomycin C hypoxic pelvic perfusion for unresectable recurrent rectal cancer: pharmacokinetic comparison of surgical and percutaneous techniques. Updates Surg. 2017; 69:403-410. https://doi.org/10.1007/s13304-017-0480-6. [PubMed]

20. Guadagni S, Palumbo G, Fiorentini G, Clementi M, Marsili L, Giordano AV, Masedu F, Valenti M. Surgical versus percutaneous Isolated Pelvic Perfusion (IPP) for advanced melanoma: comparison in terms of melphalan pharmacokinetic pelvic bio-availability. BMC Research Notes. 2017; 10:411. https://doi.org/10.1186/s13104-017-2738-y. [PubMed]

21. Begossi G, Belliveau JF, Wanebo HJ. Pelvic perfusion for advanced colorectal cancers. Surg Oncol Clin N Am. 2008; 17:825-842. https://doi.org/10.1016/j.soc.2008.04.014. [PubMed]

22. Murata S, Onozawa S, Kim C, Tajima H, Kimata R, Uchida E, Kumita S. Negative-balance isolated pelvic perfusion in patients with incurable symptomatic rectal cancer: Results and drug dose correlation to adverse events. Acta Radiol. 2014; 55:793-801. https://doi.org/10.1177/0284185113507253. [PubMed]

23. Guadagni S, Clementi M, Bencivenga M, Kusamura S, Fiorentini C, Masedu F. Palliation with a multimodality treatment including hypoxic pelvic perfusion for unresectable recurrent rectal cancer: outcomes based on a retrospective study. Updates Surg. 2018; 70:441-447. https://doi.org/10.1007/s13304-018-0592-7. [PubMed]

24. Yamada K, Ishizawa T, Niwa K, Chuman Y, Akiba S, Aikou T. Patterns of pelvic invasion are prognostic in the treatment of locally recurrent rectal cancer. Br J Surg. 2001; 88:988-993. https://doi.org/10.1046/j.0007-1323.2001.01811.x. [PubMed]

25. Bruera E, Kuehn N, Miller MJ, Selmser P, Macmillan K. The Edmonton Symptom Assessment System
(ESAS): a simple method for the assessment of palliative care patients. J Palliat Care. 1991; 7:6-9. https://doi.org/10.1177/082585979100700202. [PubMed]

26. Malfettone A, Silvestris N, Paradiso A, Mattioli E, Simone G, Mangia A. Overexpression of nuclear NHERF1 in advanced colorectal cancer: association with hypoxic microenviroment and tumor invasive phenotype. Exp Mol Pathol. 2012; 92:296-303. https://doi.org/10.1016/j.yexmp.2012.03.004. [PubMed]

27. Mambrini A, Bassi C, Pacetti $\mathrm{P}$, Torri $\mathrm{T}$, Iacono $\mathrm{C}$, Ballardini M, Orlandi M, Guadagni S, Fiorentini G, Cantore M. Prognostic factors in patients with advanced pancreatic adenocarcinoma treated with intra-arterial chemotherapy. Pancreas. 2008; 36:56-60. https://doi.org/10.1097/mpa.0b013e31812e9672. [PubMed]

28. Fiorentini G, Poddie DB, Cantore M, Rossi S, Tumolo S, Dentico P, Bernardeschi P, Guadagni S, Rossi G, Valori VM, De Simone M. Hepatic intra-arterial chemotherapy (HIAC) of high dose mitomycin and epirubicin combined with caval chemofiltration versus prolonged low doses in liver metastases from colorectal cancer: a prospective randomised study. J Chemother. 2004; 16:51-54. https://doi.org/10.1080/1120009X.2004.11782385. [PubMed]

29. Fiorentini G, Rossi S, Dentico P, Meucci F, Bonechi F, Bernardeschi P, Cantore M, Guadagni S, De Simone M. Oxaliplatin hepatic arterial infusion chemotherapy for hepatic metastases from colorectal cancer: a phase I-II clinical study. Anticancer Res. 2004; 24:2093-2096. [PubMed]

30. Bruera G, Di Staso M, Bonfili P, Galvano A, Manetta R, Coletti G, Vicentini R, Guadagni S, Ficorella C, Di Cesare E, Russo A, Ricevuto E. Dose-finding study of oxaliplatin associated to capecitabine-based preoperative chemoradiotherapy in locally advanced rectal cancer. Oncotarget. 2018; 9:17906-17914. https://doi.org/10.18632/oncotarget.24665. [PubMed]

31. Sepulveda AR, Hamilton SR, Allegra CJ, Grody W, Cushman-Vokoun AM, Funkhouser WK, Kopetz SE, Lieu C, Lindor NM, Minsky BD, Monzon FA, Sargent DJ, Singh VM, et al. Molecular biomarkers for the evaluation of colorectal cancer. Guideline from the American Society for Clinical Pathology, College of American Pathologists, Association for Molecular Pathology, and American Society of Clinical Oncology. Arch Pathol Lab Med. 2017; 141:625-657. https://doi.org/10.5858/arpa.2016-0554-CP. [PubMed]

32. Eisenhauer EA, Therasse P, Bogaerts J, Schwartz LH, Sargent D, Ford R, Dancey J, Arbuck S, Gwyther S, Mooney M, Rubinstein L, Shankar L, Dodd L, et al. New response valuation criteria in solid tumors: revised RECIST guideline (version 1.1). Eur J Cancer. 2009; 45:228-247. https://doi.org/10.1016/j.ejca.2008.10.026. [PubMed] 